\title{
CARCINOMA DE PEQUENAS CÉLULAS DO ESÔFAGO: ESTUDO CLÍNICO PATOLÓGICO DE DOIS CASOS
}

\section{Small cell carcinoma of the esophagus: clinical pathologic study of two cases}

\author{
Maria Aparecida Coelho de Arruda HENRY, Mauro Masson LERCO, \\ Walmar Kerche de OLIVEIRA, Karla Thaiza TOMAL, Ana Carolina Freitas COSTA, \\ Odair Carlito MICHELIN, Maria Aparecida Marchesan RODRIGUES
}

ABCDDV/587

Henry MACA, Lerco MM, Oliveira WK, Tomal KT, Costa ACF, Michelin OC, Rodrigues MAM. Carcinoma de pequenas células do esôfago: estudo clínico patológico de dois casos. ABCD Arq Bras Cir Dig 2008;21(1):38-40

RESUMO - Racional - O carcinoma de pequenas células primário do esôfago é tumor raro, agressivo, morfologicamente indistinguível de seu correspondente no pulmão. Objetivo - Apresentar os aspectos clínico-patológicos de dois pacientes com carcinoma de pequenas células do esôfago. Relato de casos - Paciente 1: masculino, 56 anos com disfagia progressiva há seis meses e emagrecimento, com antecedentes de tabagismo e etilismo. A endoscopia mostrou lesão vegetante dos 30 aos $40 \mathrm{~cm}$ da arcada dentária superior e o exame anatomopatológico, diagnosticou neoplasia maligna indiferenciada de pequenas células com marcadores imunoistoquímicos positivos para cromogranina e sinaptofisina, caracterizando a linhagem neuroendócrina da neoplasia. Após dois ciclos de quimioterapia (cisplatina e etoposide) associada à radioterapia ele apresentou remissão da disfagia. Paciente 2: masculino, 55 anos, com queixas de pirose, disfagia, rouquidão há seis meses, com emagrecimento de $10 \mathrm{~kg}$ no período. A endoscopia mostrou lesão vegetante à $30 \mathrm{~cm}$ da arcada dentária superior, obstrutiva. $\mathrm{O}$ exame anatomopatológico revelou carcinoma de pequenas células, com os mesmos marcadores imunoistoquímicos positivos para linhagem neuroendócrina. Tomografia computadorizada mostrou metástases hepáticas. Frente ao estadio avançado da doença optou-se pela indicação de gastrostomia. O paciente desenvolveu pneumonia e faleceu dois meses após o diagnóstico. Conclusão - A evolução dos portadores de carcinoma de pequenas células do esôfago depende do estadiamento da doença e apesar da alta agressividade biológica, este tumor apresenta boa resposta à quimioterapia associada à radioterapia.

DESCRITORES - Carcinoma de pequenas células. Esôfago. Quimioterapia.

\section{INTRODUÇÃO}

O carcinoma de pequenas células primário do esôfago (CPC) é tumor raro, agressivo, morfologicamente indistingüível de seu correspondente no pulmão $0^{1,3,7,10}$.

Dentre as neoplasias malignas que acometem o esôfago, o CPC é o de menor incidência ( 0,8 a $2,4 \%)$, cabendo a Mc Keown ${ }^{8}$ em 1952 a descrição dos dois primeiros casos deste tumor, após a análise de 9000 autópsias.

A maioria dos trabalhos a respeito do CPC inclui apenas pequeno número de pacientes, tratados por uma variedade de esquemas terapêuticos, não havendo ainda padronização de conduta a ser adotada nesta situação $0^{5,7,10,11}$.

Tendo em vista a raridade da doença, optou-se pela publicação de dois casos atendidos com esse diagnóstico.

Trabalho realizado no Departamento de Cirurgia e Ortopedia da Faculdade de Medicina de BotucatuUNESP-, Botucatu, SP, Brasil.

Endereço para correspondência: Maria Aparecida Coelho de Arruda Henry, e-mail: rhenry@ibb.unesp.br

\section{RELATO DOS CASOS}

Paciente 1 : masculino, 56 anos, branco, com disfagia progressiva há seis meses, emagrecimento de $5 \mathrm{~kg}$ e antecedentes de tabagismo e etilismo. Exame físico mostrava regular estado geral, emagrecimento, PA: 150 x $90 \mathrm{mmHg}$ e com 72 batimentos por minuto. Endoscopia digestiva alta revelou lesão vegetante, dos 30 aos $40 \mathrm{~cm}$ da arcada dentária superior (Figura 1). O exame anatomopatológico demonstrou neoplasia maligna indiferenciada de pequenas células (Figura 2), com marcadores imunoistoquímicos positivos para cromogranina e sinaptofisina, caracterizando a linhagem neuroendócrina da neoplasia. O paciente recebeu dois ciclos de quimioterapia (cisplatina e etoposide), com boa resposta clínica e remissão da disfagia durante 12 meses. Embora ele se apresentasse assintomático, foi realizada endoscopia de controle, que evidenciou lesão vegetante a $30 \mathrm{~cm}$. O exame anatomopatológico demonstrou tratar-se de carcinoma espinocelular. Tomografia computadorizada do abdome apresentou padrão dentro da normalidade, porém no tórax foram observadas imagens nodulares menores que $1 \mathrm{~cm}$ em lobos pulmonares direitos. O paciente foi submetido a novo ciclo de quimioterapia 
(cisplatina e 5-fluoracil), encontrava-se em regular estado geral no último seguimento, assintomático e recebendo alimentação por via oral após 16 meses do diagnóstico.

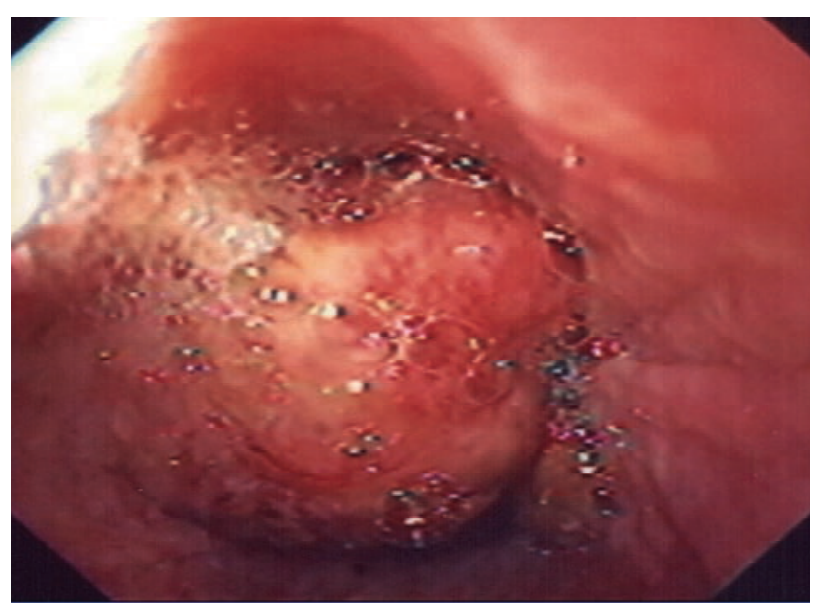

FIGURA 1 - Lesão vegetante localizada dos 30 aos $40 \mathrm{~cm}$ da arcada dentária superior (paciente 1).

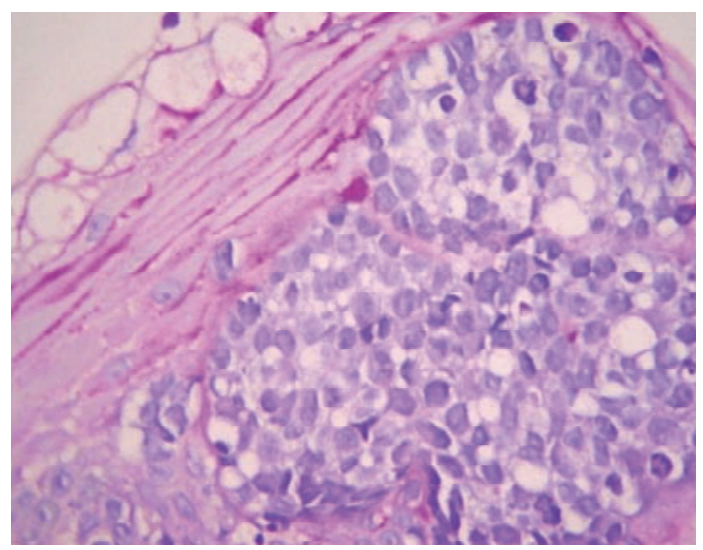

FIGURA 2 - Exame anatomopatológico característico de carcinoma de pequenas células do esôfago ( $\mathrm{H} \& \mathrm{E}$ 400x).

Paciente 2 : masculino, 55 anos, branco, com disfagia progressiva há seis meses, rouquidão, pirose e emagrecimento de $10 \mathrm{~kg}$. A endoscopia digestiva alta mostrou lesão vegetante, obstrutiva a $30 \mathrm{~cm}$ da arcada dentária superior. $\mathrm{O}$ exame anatomopatológico revelou carcinoma de pequenas células, infiltrativo com os mesmos marcadores imunoistoquímicos positivos para linhagem neuroendócrina. A tomografia computadorizada do abdome revelou múltiplas metástases hepáticas. Tendo em vista o estadio avançado (TxNxM1 - estadio IV), optou-se por conduta conservadora (gastrostomia). O paciente apresentou pneumonia dois meses após o diagnóstico, com evolução para óbito.

\section{DISCUSSÃO}

O carcinoma de pequenas células possui vasta sinonímia, sendo também denominado de "oat-cell" carcinoma, carcinoma anaplástico, carcinoma indiferenciado, apudoma, apudo-carcinoma neuroendócrino ${ }^{2}$.

Este tumor tem como característica alta agressividade, pois evolui com recidivas e metástases precoces e reduzida sobrevida ${ }^{5,9}$.

Além do pulmão, o carcinoma de pequenas células pode também acometer glândulas salivares, faringe, laringe, timo, próstata, bexiga, mama, pele e órgãos do trato gastrointestinal ${ }^{6}$.

O envolvimento digestivo tem sido bastante estudado nos últimos 50 anos, tendo sido publicados 138 artigos nesse período, nos quais 544 pacientes foram analisados nos seus aspectos clínicos ${ }^{3}$. Quanto à localização do tumor, o número de pacientes obedeceu à seguinte seqüência: esôfago 290, intestino grosso 110 , estômago 60 , vesícula biliar 46, pâncreas 21 , fígado 7 , ampola hepatopancreática 6 , vias biliares extra-hepáticas 3 e intestino delgado 1 paciente.

Nesta comunicação, apresentam-se os aspectos clínicos e patológicos de dois pacientes com carcinoma de pequenas células primário do esôfago, ambos do sexo masculino e com idades na 6 a década da vida.

As características demográficas apresentadas pelos pacientes em nada diferiram das observadas nos portadores de carcinoma espinocelular, tumor de maior incidência neste órgão ${ }^{12}$. Comentário idêntico pode ser realizado com respeito aos antecedentes (alcoolismo e tabagismo) e quadro clínico, referidos pelos pacientes.

O exame endoscópico demonstrou nos dois pacientes lesões vegetantes, extensas localizadas nos terços distais do esôfago, achados semelhantes aos relatados pela maioria dos autores ${ }^{6,11}$, cujo exame anatomopatológico mostrou características inequívocas de carcinoma de pequenas células ${ }^{6}$. A positividade dos marcadores imunoistoquímicos neuroendócrinos confirmou o diagnóstico em ambos os casos.

O estadiamento do paciente 1 demonstrou tratar-se de doença não avançada, optando-se pela quimioterapia (cisplatina e etoposide) associada à radioterapia como terapêutica inicial, conduta preconizada pela maioria dos autores $^{1,6}$. Após dois ciclos de quimioterapia, o paciente apresentou remissão completa da disfagia e ganho de peso, quadro que se mantinha até o momento da última avaliação. A endoscopia de controle revelou recidiva tumoral, com pequenas lesões vegetantes a $30 \mathrm{~cm}$ da arcada dentária superior, cujo resultado anatomopatológico foi carcinoma espinocelular.

Este achado, aparentemente paradoxal, pode ser explicado pela histogênese do carcinoma de pequenas células. Segundo Ho et al. ${ }^{4}$, esta neoplasia origina-se de células totipotentes, as "stem cells", capazes de apresentar diferentes caminhos de maturação, por exemplo, para as linhagens escamosa, glandular ou neuroendócrina. Medgysey et al. ${ }^{7}$ realizaram esofagectomia em quatro pacientes com carcinoma de pequenas células após tratamento quimioterápico e observaram tumor residual em todos os casos. O exame histopatológico das peças cirúrgicas revelou carcinoma de pequenas células em dois casos, carcinoma espinocelular 
em um e adenocarcinoma em outro paciente.

O segundo paciente deste relato apresentava doença em estado avançado, com múltiplas metástases hepáticas. As condições clínicas precárias não permitiram tratamento quimioterápico, optando-se apenas pela realização de gastrostomia, oferecendo via alternativa para alimentação. O óbito ocorreu dois meses após o diagnóstico, em decorrência de complicações pulmonares.

\section{CONCLUSÃO}

A evolução do carcinoma de pequenas células depende do estadiamento da doença, como acontece com os demais tipos de câncer e que apesar da alta agressividade biológica, este tumor responde à quimioterapia, levando à remissão da disfagia, à melhor qualidade de vida e sobrevida

Henry MACA, Lerco MM, Oliveira WK, Tomal KT, Costa ACF, Michelin OC, Rodrigues MAM. Small cell carcinoma of the esophagus: clinical pathologic study of two cases. ABCD Arq Bras Cir Dig 2008;21(1):38-40

ABSTRACT- Background-Small-cell Carcinoma of the Esophagus is a rare tumor, aggressive, and morphologically indistinguishable from its correspondent well-known tumor in the lung. Aim - To present the clinical-pathological aspects of two patients presenting small-cell carcinoma of the esophagus. Cases report - Patient 1- a 55-year-old man presenting progressive dysphagia for 6 months, weight loss, and previous smoking and alcohol abuse history. Endoscopy showed a polypoid lesion, located 30 to $40 \mathrm{~cm}$ from the superior arcade. Anatomopathological analysis revealed undifferentiated small-cell carcinoma and positive immunohistochemical staining for neuroendocrine markers, including chromogranin and synaptophysin. The patient presented dysphagia remission after two cycles of chemotherapy (cisplatin and etoposide) and radiotherapy. Patient 2 - a 55-year-old man complaining pirosis, dysphagia, and hoarseness for 6 months, associated to a $10 \mathrm{~kg}$ weight loss. Endoscopy showed an obstructive polypoid lesion located $30 \mathrm{~cm}$ from the superior dental arcade. Anatomopathological study revealed small-cell carcinoma and positive immunohistochemical staining for neuroendocrine tumor. Computed tomography showed liver metastases. Considering the advanced stage of the tumor, gastrostomy was performed. The patient developed pneumonia and died within two months. Conclusion - The evolution of patients presenting small-cell carcinoma of the esophagus depends on the tumor staging. Despite of its aggressiveness, the respective tumor responds positively to combined chemo-radiotherapy.

HEADINGS - Small-cell carcinoma. Esophagus. Chemotherapy.

\section{REFERÊNCIAS}

1. Bennouna J, Bardet E, Deguiral P, Douillard JY. Small cell carcinoma of the esophagus. Analysis of 10 cases and review of the published data. Am J Clin Oncol 2000; 23 (5):455-9.

2. Bogomoletz WV. Rare and secondary(metastatic) tumors. In: Whitehead R. Gastrointestinal and esophageal pathology. Churchil Livingstone. Second Edition 1995 p.813-822.

3. Brenner B, Tang LH, Klimstra DS, Kelsen DP. Small cell carcinomas of the gastrointestinal tract: a review. J Clin Oncol 2004; 22(13): 2730-9.

4. Ho KJ, Herrera GA, Jones JM, Alexander CB. Small cell carcinoma of the esophagus: evidence of a unified histogenesis. Hum Pathol 1984; 15: 460-8.

5. Hosokawa A, ShimadaY, Matsumura Y, Yamada Y, Muro K, Hamaguchi T, Igaki H, Tachimori Y, Kato H, Shirao K. Small cell carcinoma of the esophagus. Analysis of 14 cases and literature review. Hepato-Gastroenterology 2005; 52 : 1738-41.

6. Kitlaw SY, Fok M, Lam KY, Loke SL, Ma LT, Wong J. Small cell carcinoma of the esophagus. Cancer 1994; 73 (12): 2894-9.
7. Medayesy DC, Wolff RA, Putnam JB, Ajani JA. Small cell carcinoma of the esophagus. The University of Texas MD. Anderson Cancer Center experience and literature review. Am Cancer Soc 2000; 88(2): 262-6.

8. Mc Keown F. Oat cell carcinoma of the esophagus. J Pathol Bacteriol 1952; 64:889-91.

9. Tobari S, Ikeda Y, Kurihara H, Takami H, Akinaga K, Kodaira S. Effective treatment with chemotherapy and surgery for advanced small cell carcinoma of the esophagus. Hepato-Gastroenterology 2004; 51: 1027-9.

10. Wu Z, Ma JY, Yang JJ, Zhao YF, Zhang SF. Primary small cell carcinoma of esophagus : report of 9 cases and review of literature. World J Gastroenterol 2004; 15(10): 3680-2.

11. Yachida S, Matsushita K, Usuki H, Wanibuchi H, Maeba T, Maeta H. Long term survival after resection for small cell carcinoma of the esophagus. Ann Thoracic Surg 2001;72:596-7.

12. Zilberstein B, Faintuch J, Pinotti HW. Câncer do esôfago. In: Pinotti HW. Tratado de clínica cirúrgica do aparelho digestivo. São Paulo: Atheneu: 1994. Cap 15, p. 416-25. 